\title{
High level of GHR nuclear translocation in skeletal muscle of a hyperplasic transgenic zebrafish
}

\author{
Marcio A Figueiredo', Robert T Boyle ${ }^{2}$, Juliana Z Sandrini', Antonio S Varela Junior ${ }^{3}$ \\ and Luis F Marins ${ }^{1}$ \\ ${ }^{1}$ Laboratório de Biologia Molecular, Instituto de Ciências Biológicas, Universidade Federal do Rio Grande - FURG, \\ Avenue Italia, Km 8, CEP 96203-900, Rio Grande, RS, Brazil \\ ${ }^{2}$ Laboratório de Cultura Celular, Instituto de Ciências Biológicas, Universidade Federal do Rio Grande - FURG, \\ Rio Grande, RS, Brazil \\ ${ }^{3}$ Laboratório de Histologia, Instituto de Ciências Biológicas, Universidade Federal do Rio Grande - FURG, \\ Rio Grande, RS, Brazil
}

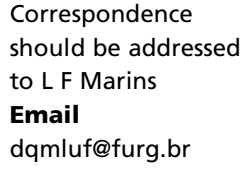

\begin{abstract}
It has been reported that nuclear translocation of growth hormone receptor (GHR) may directly activate cell proliferation in mammals and birds. However, this phenomenon has not yet been described in fish. Recently, we have developed a transgenic zebrafish that overexpresses GHR in a muscle-specific manner. Considering that this transgenic model exhibits hyperplasic muscle growth, the present work aims at verifying the relationship between GHR nuclear translocation and muscle cell proliferation. This relationship was evaluated by the phosphorylation state of the proliferative MEK/ERK pathway, expression of nuclear import-related genes, immunostaining of phospho-histone $\mathrm{H} 3$ (PH3) as a proliferation marker, and nuclear GHR localization. The results showed a significant decrease in the phosphorylation state of ERK1/2 proteins in transgenics. Moreover, there was an increase in expression of three out of four importin genes analyzed parallel to a large flow of GHR displacement toward and into the nucleus of transgenic muscle cells. Also, transgenics presented a marked increase in $\mathrm{PH} 3$ staining, which indicates cell proliferation. These findings, as far as we know, are the first report suggesting a proliferative action of GHR in fish as a consequence of its increased nuclear translocation. Thus, it appears that the nuclear migration of cytokine receptors is a common event among different taxonomic groups. In addition, the results presented here highlight the possibility that these membrane proteins may be involved more directly than previously thought in the control of genes related to cell growth and proliferation.
\end{abstract}

\section{Key Words \\ - Danio rerio \\ - growth hormone receptor \\ - hyperplasia \\ - nuclear transport}

Journal of Molecular

Endocrinology

(2016) 56, 47-54

\section{Introduction}

Growth hormone $(\mathrm{GH})$ is a pluripotent hormone produced and secreted by vertebrate pituitary glands. The hormone's actions are mediated via the GH receptor (GHR), which is widely expressed by GH target cells. GHR is the key regulator of post-natal growth and holds important actions over metabolic, reproductive, gastrointestinal, cardiovascular, hepatobiliary, and renal systems (Lichanska \& Waters 2008). Concerning muscular tissue, GH and insulin-like growth factor 1 (IGF1) seem to regulate hypertrophy and hyperplasia, these processes being influenced by myogenic regulatory factors (MRFs) (Sabourin \& Rudnicki 2000, Hawke \& Garry 2001).

Published by Bioscientifica Ltd. 
GHR is a class- 1 cytokine membrane receptor and it is assumed to trigger intracellular signalization by the JAK2/STAT pathway (Argetsinger \& Carter-Su 1996, Moutoussamy et al. 1998, Waters et al. 2006). However, it has been reported that GHR may signal through additional JAK2-independent mechanisms (Zhu et al. 2002, Barclay et al. 2010). The MEK/ERK signaling pathway is an example of JAK2-independent signaling, which is implicated in cell proliferation induced by GH (Liang et al. 1999). Alternatively, significant amounts of GHR molecules have been found in the cell's interior, including its intriguing nuclear localization (Lobie et al. 1991, 1994, Mertani et al. 2003). The processes leading to GHR nuclear localization is believed to depend upon the receptor's escape from degradation mechanisms and its subsequent transportation to the nucleus by the classic importin system (Bryant \& Stow 2005, Swanson \& Kopchick 2007, Conway-Campbell et al. 2008). Nuclear localization of GHR seems to be a common characteristic of tissues and cells exhibiting high proliferative levels (ConwayCampbell et al. 2007, Martínez-Moreno et al. 2011).

Studies addressing the nuclear translocation of GHR have almost exclusively used in vitro models. However, in vivo models could shed more light on this fascinating mechanism. Recently, we developed a transgenic zebrafish (Danio rerio) strain overexpressing approximately 100 times more GHR in skeletal muscular tissue (Figueiredo et al. 2012). This in vivo model can be an interesting tool to study the relationship between GHR nuclear localization and muscle cell proliferation. Indeed, individuals from this transgenic strain show an increased number of muscle fibers with no weight gain compared to non-transgenics. This hyperplasic condition was related to increase in MRF expression. However, the JAK2/STAT signaling pathway was significantly diminished in transgenics, leading to a decrease in IGF1 transcription levels (Figueiredo et al. 2012). Altogether, these observations suggest that GHRinduced hyperplasia is taking place for some JAK2/STATindependent pathway. Thus, the objective of this study was to determine whether there is a relationship between the observed hyperplasia in our transgenic zebrafish strain and an increase in GHR nuclear translocation in muscle cells overexpressing this membrane receptor.

\section{Material and methods}

\section{Transgenic fish}

The GHR-transgenic zebrafish strain used here holds a genetic construct assembled by GHR cDNA under transcriptional control of the myosin light chain 2 (mylz2) promoter (Figueiredo et al. 2012). All sequences used were obtained directly from the zebrafish. Additionally, this strain carries a reporter transgene containing the same promoter driving the expression of the red fluorescent protein (DsRed) from Discosoma sp. (Fig. 1). This strategy allowed transgenic identification under ultraviolet light as soon as they hatched. Mating hemizygous transgenic males with non-transgenic females produced transgenic and non-transgenic fish from the same breed in a Mendelian proportion.

\section{RNA extraction and qPCR}

Forty-five-day-old fish had their total RNA extracted from skeletal muscle tissue by the TRIzol reagent method (Invitrogen) according to the manufacturer's instructions. The extracted RNA was treated with DNAse I Amplification Grade (Invitrogen) and used as a template for cDNA
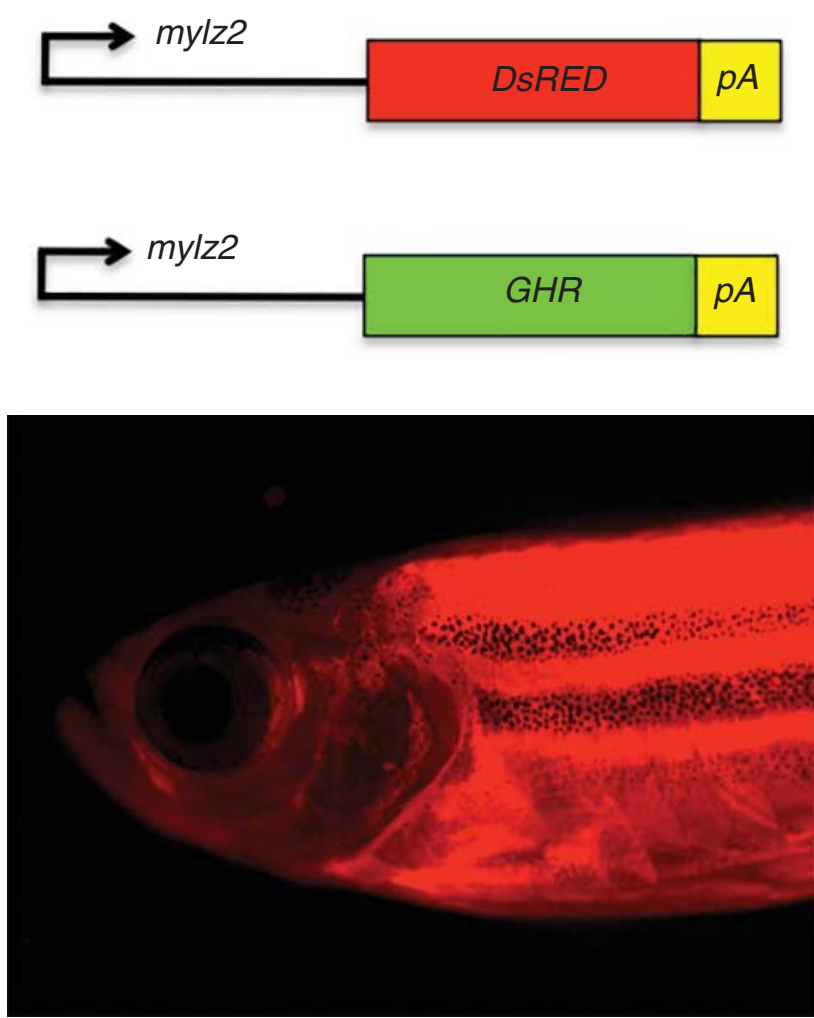

Figure 1

Schematic representation of transgenes used for production of the GHRtransgenic zebrafish (Danio rerio) strain. The myosin light chain 2 (mylz2) promoter was used to drive expression of both GHR (target gene) and $D S R E D$ (red fluorescence as transgenesis marker). ' $p A^{\prime}$ represents the termination signal. Transgenic zebrafish express both GHR and red fluorescence only in skeletal muscle tissue. A full colour version of this figure is available at http://dx.doi.org/10.1530/JME-15-0185.

Published by Bioscientifica Ltd 
synthesis through the high capacity cDNA reverse transcription kit (Applied Biosystems), following manufacturers' protocols. Expression of four importin genes (impa1, impa3, impB1 and impB2) was analyzed by quantitative Real Time PCR (qPCR). Seven individuals from each experimental group were used. Gene-specific primers (Table 1) were designed using the software Primer Express 3.0 (Applied Biosystems), based upon sequences available at GenBank (http://www.ncbi.nlm.nih.gov). The qPCR reactions were performed in a 7500 Real Time PCR System platform (Applied Biosystems) using the Platinum SYBR Green qPCR SuperMix-UDG kit (Invitrogen). Each sample was analyzed in triplicate to avoid plate deviations. Serial dilutions were made for all primers to determine the qPCR reaction efficiency. PCR reaction conditions were $50^{\circ} \mathrm{C} / 2 \mathrm{~min}, 95^{\circ} \mathrm{C} / 2 \mathrm{~min}$, followed by 40 cycles of $95^{\circ} \mathrm{C} / 15 \mathrm{~s}$ and $60^{\circ} \mathrm{C} / 30 \mathrm{~s}$. Expression of target genes was normalized by the elongation factor 1 alpha $(e f 1 a)$ gene expression, which showed no significant differences among the experimental groups (data not shown). Data were analyzed by relative expression, according to the mathematical model proposed by Fernandes et al. (2006).

\section{Western blot analysis}

Muscular tissue was collected from four animals from each experimental group, lysed in a protein homogenization solution (100 mM Tris- $\mathrm{HCl}, 2 \mathrm{mM}$ EDTA, $5 \mathrm{mM} \mathrm{MgCl}_{2}$, and $250 \mathrm{ml}$ MilliQ water; $\mathrm{pH}$ 7.75), and centrifuged for $20 \mathrm{~min}$ at $2000 \mathrm{~g}$ at $4{ }^{\circ} \mathrm{C}$. The supernatant was recovered and centrifuged for $45 \mathrm{~min}$ at $10000 \mathrm{~g}$ at $4{ }^{\circ} \mathrm{C}$. The supernatant was recovered, and its protein content was determined by the Qubit method (Invitrogen). Samples were analyzed using SDS-PAGE in 7.5\% gels using migration buffer (124 mM Trisma-base, $1 \mathrm{M}$ glycine, $0.5 \%$ SDS, and $500 \mathrm{ml}$ MilliQ water; $\mathrm{pH}$ 8.3) in miniVE Electrophoresis and Electrotransfer Unit (Amersham Bioscience, São Paulo, Brazil). Each lane contained $30 \mu \mathrm{g}$ of protein or $5 \mu \mathrm{l}$ of MagicMark XP Western Standard (Novex, São Paulo, Brazil). Samples were analyzed under reducing conditions (5\% 2-mercaptoethanol). After electrophoresis, gels were equilibrated in transfer buffer (25 mM Tris- $\mathrm{HCl}, 192 \mathrm{mM}$ glycine, and 20\% methanol (v/v); $\mathrm{pH} 8.3$ ) for $30 \mathrm{~min}$ and electro-transferred (up to $1.0 \mathrm{~A}, 30 \mathrm{~min}$ ) in Trans-Blot Turbo Blotting System (BIO$\mathrm{RAD}$ ) to a $0.2-\mu \mathrm{m}$ PVDF membrane (Invitrogen), according to the manufacturer's instructions. Membranes were dried and re-wet with methanol followed by two 20-ml water washes for $5 \mathrm{~min}$. For the protein immunodetection process, we used the Western Breeze Chromogenic western blot Immunodetection system anti-rabbit kit (Novex, Brazil), according to the manufacturer's instructions. The rabbit monoclonal primary antibody used was p44/42 MAPK (Erk1/2) Rabbit mAb (Cell Signaling, São Paulo, Brazil) for total Erk1/2, and Phospho-p44/42 MAPK (Erk1/2) XP Rabbit mAb (Cell Signaling) for phosphorylated Erk1/2. All primary antibodies were used at a 1:1000 dilution.

\section{Immunohistochemistry}

Seven zebrafish from each experimental group were euthanized with Tricaine methosulfonate $(0.5 \mathrm{mg} / \mathrm{ml})$ for collection of muscle tissue. Samples were immediately fixed $(6 \mathrm{~h})$ in $4 \%$ paraformaldehyde in PBS and preserved in $70 \%$ ethanol. Tissue samples were dehydrated (ethanol), diafanized (xylol), and impregnated (Paraplast Xtra; Sigma) using an automated vacuum tissue processor (Leica, São Paulo, Brazil). Transverse histological sections $(4 \mu \mathrm{m})$ from muscle fibers were obtained with an automated rotatory microtome (Leica). The sections were deparaffinized and rehydrated in xylene and ethanol series. Antigen retrieval was carried out in a microwave oven (boiling for at least $20 \mathrm{~min}$ in citrate buffer), cooled slowly, and then transferred to PBS at $4{ }^{\circ} \mathrm{C}$. The slides were then blocked for $1 \mathrm{~h}$ in $5 \%$ normal goat serum $+\mathrm{BSA}$ at $4{ }^{\circ} \mathrm{C}$. Individual sections were washed in PBS and covered with $3 \mu \mathrm{g} / \mathrm{ml}$ of GHR antibody (MAB 263) FITC (Santa Cruz Biotechnology) and $4 \mu \mathrm{g} / \mathrm{ml}$ of PH3 Antibody (Ser 10)-R (Santa Cruz Biotechnology). Antibodies were diluted in PBS. The slides were placed in a humidified chamber and kept in the dark overnight at $4{ }^{\circ} \mathrm{C}$. Next day, slides

Table 1 Gene specific primers used for qPCR analyses.

\begin{tabular}{l} 
Gene \\
\hline ef1a \\
impa1 \\
impa3 \\
impB1 \\
impB2
\end{tabular}

\begin{tabular}{l} 
Forward primer \\
\hline $5^{\prime}$-gggcaagggctccttcaa-3' \\
$5^{\prime}$-cccacactcatctgccttctg-3' \\
$5^{\prime}$-tccttccatcccataacctt-3' \\
$5^{\prime}$-gcacgcagggagatcaaga-3' \\
$5^{\prime}$-gacccaacacacccaaaactct-3'
\end{tabular}

\begin{tabular}{l} 
Reverse primer \\
\hline $5^{\prime}$-cgctcggccttcagtttg-3' \\
$5^{\prime}$-gcaggtgtccgcaagca-3' \\
$5^{\prime}$-ttcggcacaggttgacaatg-3' \\
$5^{\prime}$-ctgggccggtatgtctctgt-3' \\
$5^{\prime}$-cacgtatcccagtcgaccaat-3' \\
\hline
\end{tabular}

\begin{tabular}{l}
\hline GenBank \\
\hline NM_131263 \\
BC075790 \\
BC055253 \\
NM_001037702 \\
BC080218
\end{tabular}


were thoroughly rinsed with PBS and re-covered with $4 \mu \mathrm{g} / \mathrm{ml}$ Anti-Rabbit-IgG-Atto $647 \mathrm{~N}$ (Sigma) for at least $3 \mathrm{~h}$. Slides were rinsed again with PBS and covered with $1 \mu \mathrm{g} / \mathrm{ml}$ DAPI (Sigma) for nuclei labeling. Finally, slides were mounted with Fluoroshield (Sigma) and $0.7 \mathrm{~mm}$ coverslip.

Images were acquired with BX52 epi-flourescent microscope (Olympus) or TCS SP8 scanning spectral confocal microscope (Leica). For confocal images, settings were fixed at the beginning of both acquisition and analysis steps and were unchanged. Images were acquired sequentially using the following settings: FITC (green) channel (confocal PMT $=500-560 \mathrm{~nm}$ ), Atto 647 (red) channel (confocal PMT $=650-700 \mathrm{~nm}$ ), and DAPI (blue) channel (confocal $\mathrm{HyD}=410-470 \mathrm{~nm}$ ).

\section{Colocalization analysis}

The presence of GH receptor within the myocyte nuclei was analyzed using CoLocalizer Express Software (CoLocalization Research Software, Tokyo, Japan). The software determined the degree of colocalization of green channel signal (GHR) and blue channel signal (myocyte nucleus) within each selected nucleus, using the following algorithm according to the software manual (http://www. colocalizer.com/probasics.html):

$m_{1}=\frac{\sum_{i} S 1_{i, \text { coloc }}}{\sum_{i} S 1_{i}} \quad m_{2}=\frac{\sum_{i} S 2_{i, \text { coloc }}}{\sum_{i} S 2_{i}}$

Colocalization coefficients $m_{1}$ and $m_{2}$ describe the contribution of each channel to the image ROI. They are not sensitive to the intensities of signals and can be used when the numbers of objects are not equal: where S1 represents signal intensity of pixels in the channel 1 and S2 represents signal intensity of pixels in the channel 2 (Zinchuk et al. 2007). The term $m_{1}$ relates to the percentage of blue pixels from the selected region (nucleus) that also contains a green channel signal (GHR), thus determining their amount of colocalization. The result $m_{1}$ is a value that states what percentage of the two-dimensional area of nucleus also contains GHR. The $m_{1}$ values obtained from six unique transgenic fish and from seven unique WT were compared to negative controls. The negative control group represents the noise in our measurement system. These negative controls were obtained from randomly selected nuclei from transgenic and WT fish $(n=10)$ and performing the colocalization analysis only using the blue channel images without the green channel overlay. Theoretically, this group should show no degree of colocalization. The small signal seen in the negative control column is a sum of common fluorescent noise, principally fluorophore cross-talk, which can reveal the limitations of the optical system.

\section{Statistical analysis}

Student's $t$-test was used for paired comparisons between transgenic and non-transgenic fish for both gene expression and western blot data analyses. Results were expressed in mean \pm s.e.m. One-way ANOVA was used for colocalization analysis. In all cases, the adopted $\alpha$ was 0.05 .

\section{Results}

Western blot analysis was carried out to evaluate the phosphorylation state of the MEK/ERK intracellular signaling pathway. Phosphorylated ERK1/2 was significantly reduced in muscle of GHR-transgenics (0.044 \pm 0.009), when compared to non-transgenic controls $(0.193 \pm 0.086)$ (Fig. 2). Expression analyses of nuclear import-related genes revealed that impa1, impa3, and impB1 increased twofold in transgenics, while impB2 was not altered (Fig. 3). Analyses of confocal images indicated the GHR presence in membranes of muscle cells in both experimental groups, with a significant increase in the nuclear region of transgenics (Fig. 4F) when compared with non-transgenics (Fig. 4B). In addition, the proliferation marker PH3 was significantly increased in transgenics (Fig. 4G), when compared to non-transgenics (Fig. 4C). Colocalization GHR/DAPI analysis confirmed

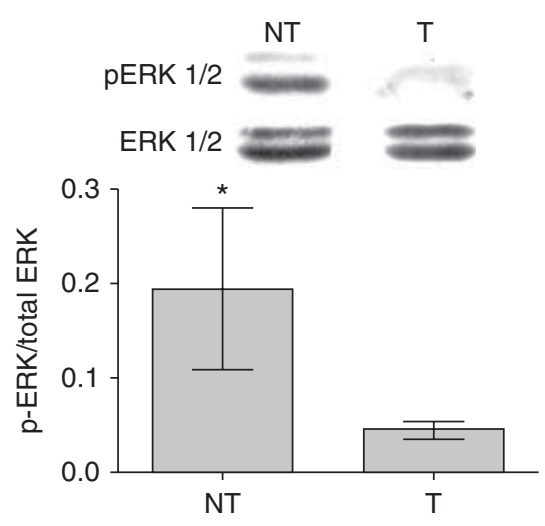

Figure 2

Western blot analyses of ERK $1 / 2$ proteins compare GHR-transgenic (T) and non-transgenic (NT) zebrafish. Graph shows pERK1/2 data normalized by total ERK $1 / 2$. Asterisk represents statistically significant differences $(P<0.05 ; n=4)$.

Published by Bioscientifica Ltd 


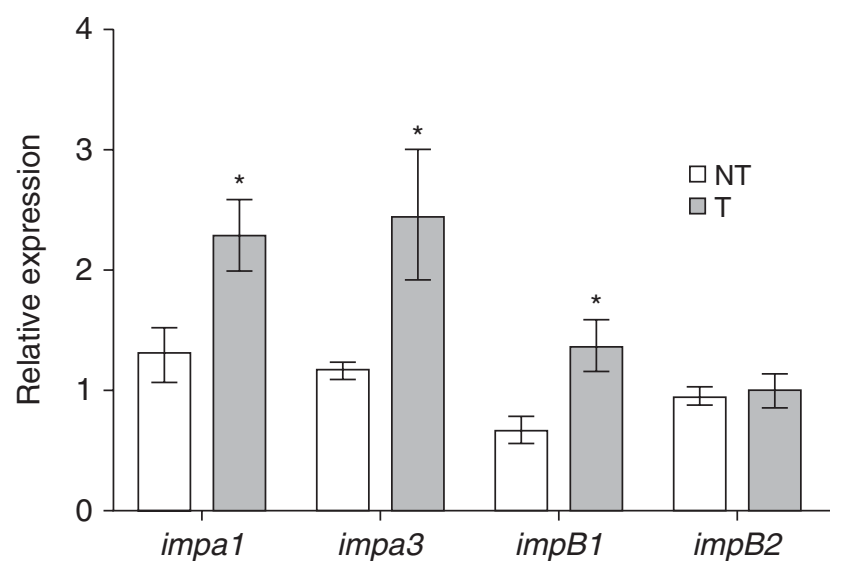

Figure 3

Relative expression of nuclear import related genes compare GHRtransgenic $(\mathrm{T})$ and non-transgenic (NT) zebrafish. Asterisks represent statistically significant differences $(P<0.05)$. In all cases $n=7$.

that $78.6 \%$ of the two-dimensional area of transgenic nuclei showed evidence of the receptor, while only $49.1 \%$ of the nuclear area of non-transgenic fish showed the same characteristic (Fig. 5). Finally, a more detailed picture of the GHR migration toward the nuclear region is shown in Fig. 6, where it is possible to observe the receptor surrounding the nuclear membrane.
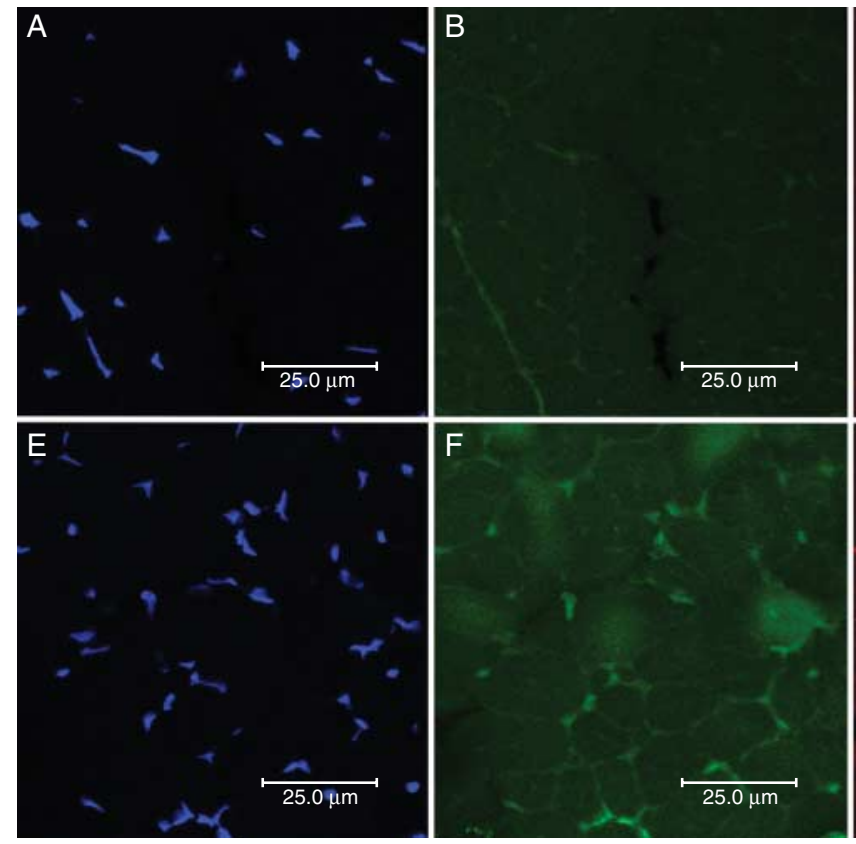

Figure 4

Confocal images from skeletal muscle sections of non-transgenic ( $A, B, C$, and $D)$ and transgenic $(E, F, G$, and $H)$ zebrafish. All sections were triple labeled using DAPI for nuclei staining (blue), GHR antibody (green) and phospho-

\section{Discussion}

The majority of what is known regarding the intracellular signaling of the somatotrophic axis has been elucidated through cellular models. In vitro studies provide important evidences and are indispensable in illuminating specific physiological mechanisms. Unfortunately, much information obtained from these studies cannot be extrapolated to the organismal level due, in part, to the great complexity of interactions that occur at the intermediate systemic levels. The use of in vivo models provides additional information, since the operation of specific mechanisms can be evaluated under the influence of intraand extracellular signals in association with environmental parameters. In this study, we employed a transgenic zebrafish model overexpressing GHR specifically in skeletal muscle cells. This transgenic strain has been previously characterized as hyperplasic regarding muscle growth (Figueiredo et al. 2012). Here, the relationship between muscle cell proliferation and GHR overexpression was tested through analyses of phosphorylation state of the proliferative MEK/ERK pathway, expression of nuclear import-related genes, immunostaining of the proliferative marker PH3, and nuclear localization of GH receptor.

The MEK/ERK pathway represents an alternative pathway for GH signaling as well as for IGF1 (Herrington
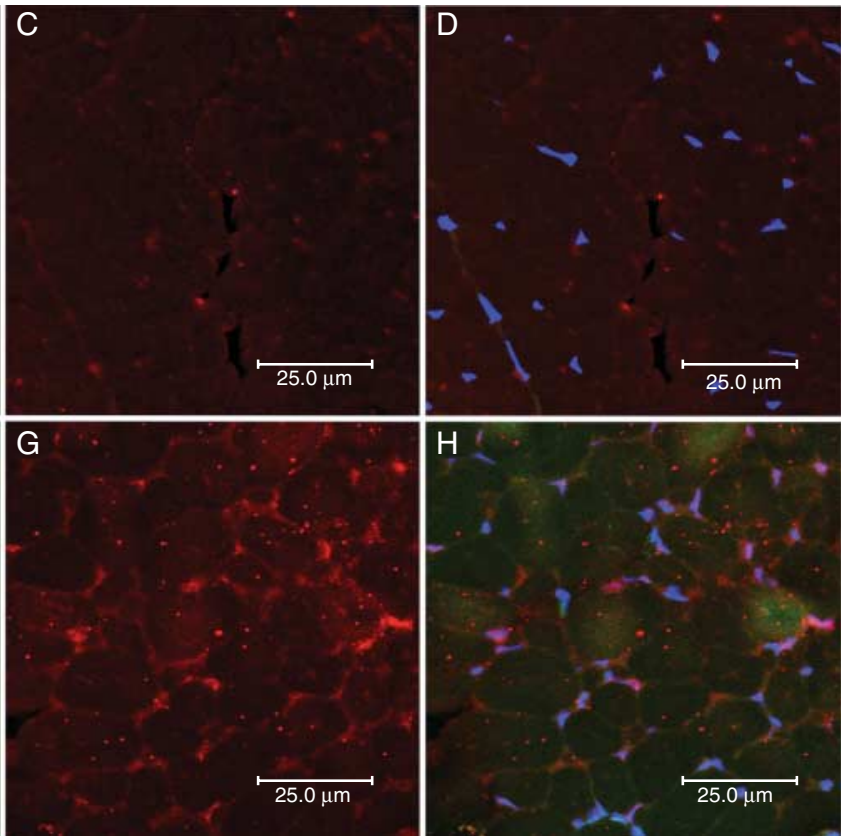

histone $\mathrm{H} 3$ ( $\mathrm{PH} 3$ ) antibody (red). ( $\mathrm{D}$ and $\mathrm{H}$ ) are overlaid images from non-transgenic and transgenic respectively. Scale bars $=25 \mu \mathrm{m}$. A full colour version of this figure is available at http://dx.doi.org/10.1530/JME-15-0185.

Published by Bioscientifica Ltd. 


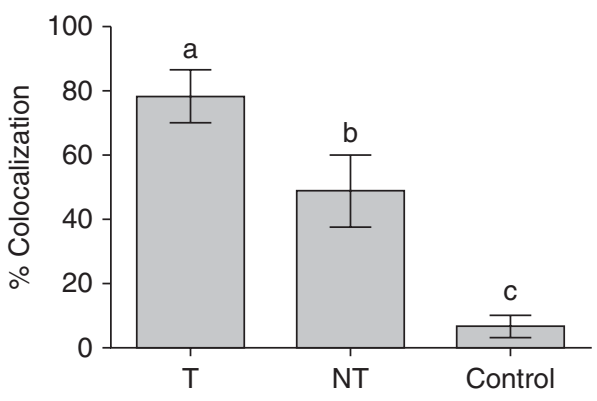

Figure 5

Percentage of GHR/DAPI (nuclei) colocalization in skeletal muscle cells of GHR-transgenic (T) and non-transgenic (NT) zebrafish. Control group (C) represents system noise (see 'Material and methods' section). Different letters represent statistical differences determined by one way ANOVA. Transgenics: $n=7$, non-transgenics: $n=6$, and controls: $n=10$.

\& Carter-Su 2001), and it is related to proliferative and cell differentiation processes (Coolican et al. 1997, Clemmons 2009). MEK/ERK signaling pathway activation occurs after the hormone binding to its receptor, leading to tyrosine phosphorylation mediated by serine/threonine kinases such as Shc, Raf, and MAPK (Chiou et al. 2007). Among these factors, MAPK is crucial for regulation of cell functions in response to mitotic stimuli (Seger \& Krebs 1995, Robinson \& Cobb 1997). There are three MAPK classes and in the present work, MEK and ERK were investigated. We performed a western blot analysis to measure the phospho-ERK1/2 concentrations in the muscle tissue. A very lower quantity of phosphorylated ERK1/2 in transgenics was observed when compared to non-transgenics, indicating a substantial reduction of this signaling cascade of approximately $77 \%$. This observation suggests that hyperplasia previously found in GHRtransgenic strain was not due to the activation of MEK/ERK signaling pathway. Thus, the main question that must be answered is how GHR overexpression might be increasing MRF transcription and consequently inducing hyperplasia?

It has been shown that the complex assembled by the binding of GH to its receptor, localized at the cell surface, is internalized and redistributed to different subcellular compartments (Roupas \& Herington 1989). The mechanism by which GH/GHR complex is translocated into the nucleus still has not been well established, and it seems that this type of translocation is not exclusive to GHR. Other receptors closely related to GHR are also translocated into cell's nucleus (Bryant \& Stow 2005, Krolewski 2005, Carpenter \& Liao 2009, Wang \& Hung 2009), and these translocations have been related to cell proliferation (Reilly \& Maher 2001, Wang et al. 2010). The nuclear translocation process, in mammals, requires importin- $\beta$ as described for FGFR1, EGFR, and ErbB2 receptors (Reilly \& Maher 2001, Giri et al. 2005, Lo et al. 2006). Moreover, GHR transport into nuclei of murine hematopoietic cells $(\mathrm{Ba} / \mathrm{F} 3)$ seems to be mediated by the classic heterodimer importin a/B mechanism (Conway-Campbell et al. 2008). In the present study, we observed a significant twofold increase in expression in three out of four importin genes analyzed, suggesting molecular transport into the nucleus. GHR has been observed in proliferative cells' nuclei from chick testis (Martínez-Moreno et al. 2011), as well as in BaF/3 cells stably expressing GHR (Conway-Campbell et al. 2007). Thus, it is likely that the increased expression of importin

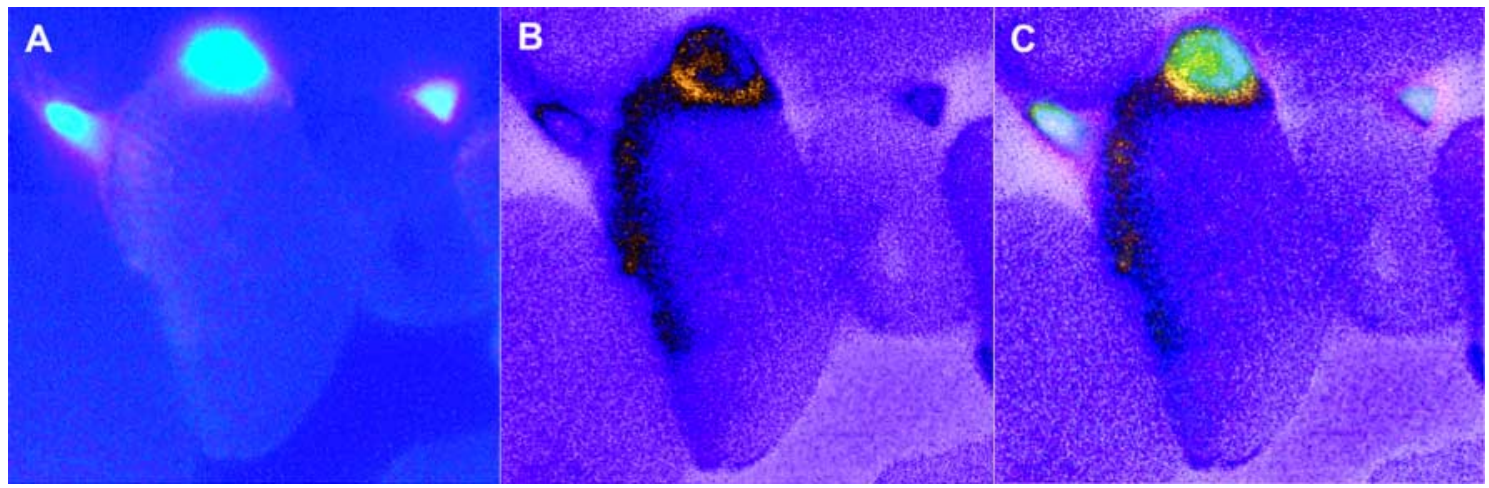

\section{Figure 6}

Representative epifluorescent micrograph showing GHR migration and concentration within the nuclei of transgenic zebrafish muscle fibers. (A) Original 32-bit DAPI channel co-label confirms the highest signal levels indeed originate from the cell nuclei. (B) The original 32-bit FITC channel RGB image was converted to 8-bit grayscale, and then the ICA lookup table from NIH Image was applied to visually enhance the differences in signal levels. Yellow corresponds to the highest concentration of GHR, orange is intermediate concentrations, and dark brown are the lowest detectable levels of GHR. (C) Superimposed images. A full colour version of this figure is available at http://dx.doi.org/10.1530/JME-15-0185.

Published by Bioscientifica Ltd. 
genes observed here might be related to nuclear transport of the overexpressed receptor in muscle cells of our transgenic strain.

In order to verify whether GHR overexpression resulted in an increased transport of this receptor to the nucleus, an immunohistochemical analysis was performed. A quantitative analysis the GHR labeling was performed comparing transgenic and non-transgenic groups. We observed that nuclear transport of the GHR also occurs in non-transgenic fish, but at a significantly lower intensity. These results indicate that overexpression of GHR resulted in an increase in the nuclear transport of this receptor. Beyond that, the proliferative state of transgenic muscle cells was confirmed by the increased staining of phosphorylated histones in this experimental group. Together, these results permit us to hypothesize that nuclear translocation of the receptor could be leading to an increased cell proliferation in muscle of GHRtransgenic zebrafish. Figure 6 shows more details about nuclear transport of the GHR in a muscle fiber from a GHRtransgenic fish. One can clearly observe the presence of the receptor in the cytoplasm and an increasing intensity gradient approaching the nucleus, where the highest concentration of the receptor is detected.

Nuclear internalization of cytokine receptors has been associated with cellular proliferation and, in most cases, to cancer (Aleksic et al. 2010, Wang et al. 2010, Wang \& Hung 2012, Wu et al. 2012). According to Conway-Campbell et al. (2008), nuclear GHR is involved in transcriptional regulation, exhibiting many proprieties normally associated with transcription factors. However, GHR interaction with transcriptional coactivator molecules is likely to be necessary to exert any transcriptional activity, as this receptor does not exhibit DNA binding domains. Among these molecules, the coactivator activator (CoAA) supplies a putative mechanism to nuclear GHR transcriptional activity in mammals and there are data demonstrating that CoAA increases the transcriptional activity of many transcription factors (Auboeuf et al. 2004). Identification of a fish CoAA could be helpful to determine the GHR's mechanism of action in the cell's nucleus of this vertebrate group.

This study provides compelling evidence that nuclear translocation of the GHR may be associated with increased cell proliferation in fish, as already observed for birds and mammals. The occurrence of GHR nuclear translocation in fish and its possible action as an ancillary transcription factor is an indication of the high degree of conservativeness of this mechanism from an evolutionary point of view. Taking this into consideration, it is possible that the role of this receptor is not restricted only to the triggering of intracellular signaling cascades from its interaction with the GH. More than that, cytokine receptors seem to be more directly involved in the regulation of genes related to cellular growth and proliferation.

\section{Declaration of interest}

The authors declare that there is no conflict of interest that could be perceived as prejudicing the impartiality of the research reported.

\section{Funding}

This work received financial support from CNPq (Conselho Nacional de Desenvolvimento Científico e Tecnológico, proc. no. 471437/2009-3) and CAPES (Coordenação de Aperfeiçoamento de Pessoal de Nível Superior). L F M is a research fellow from CNPq (Proc. No. 304675/2011-3).

\section{References}

Aleksic T, Chitnis MM, Perestenko OV, Gao S, Thomas PH, Turner GD, Protheroe AS, Howarth M \& Macaulay VM 2010 Type 1 insulin-like growth factor receptor translocates to the nucleus of human tumor cells. Cancer Research 70 6412-6419. (doi:10.1158/0008-5472.CAN10-0052)

Argetsinger LS \& Carter-Su C 1996 Mechanism of signaling by growth hormone receptor. Physiological Reviews 76 1089-1107.

Auboeuf D, Dowhan DH, Li X, Larkin K, Ko L, Berget SM \& O’Malley BW $2004 \mathrm{CoAA}$, a nuclear receptor coactivator protein at the interface of transcriptional coactivation and RNA splicing. Molecular and Cellular Biology 24 442-453. (doi:10.1128/MCB.24.1.442-453.2004)

Barclay JL, Kerr LM, Arthur L, Rowland JE, Nelson CN, Ishikawa M, d'Aniello EM, White M, Noakes PG \& Waters MJ 2010 In vivo targeting of the growth hormone receptor (GHR) box1 sequence demonstrates that the GHR does not signal exclusively through JAK2. Molecular Endocrinology 24 204-217. (doi:10.1210/me.2009-0233)

Bryant DM \& Stow JL 2005 Nuclear translocation of cell surface receptors: lessons from fibroblast growth factor. Traffic 6 947-954. (doi:10.1111/ j.1600-0854.2005.00332.x)

Carpenter G \& Liao H-J 2009 Trafficking of receptor tyrosine kinases to the nucleus. Experimental Cell Research 315 1556-1566. (doi:10.1016/ j.yexcr.2008.09.027)

Chiou M-J, Wang Y-D, Kuo C-M, Chen J-C \& Chen J-Y 2007 Functional analysis of mitogen-activated protein kinase-3 (MAPK3) and its regulation of the promoter region in zebrafish. DNA and Cell Biology 26 781-790. (doi:10.1089/dna.2007.0613)

Clemmons DR 2009 Role of IGF1 in skeletal muscle mass maintenance. Trends in Endocrinology and Metabolism 20 349-356. (doi:10.1016/j.tem. 2009.04.002)

Conway-Campbell BL, Wooh JW, Brooks AJ, Gordon D, Brown RJ, Lichanska AM, Chin HS, Barton CL, Boyle GM, Parsons PG et al. 2007 Nuclear targeting of the growth hormone receptor results in dysregulation of cell proliferation and tumorigenesis. PNAS 104 13331-13336. (doi:10.1073/pnas.0600181104)

Conway-Campbell BL, Brooks AJ, Robinson PJ, Perani M \& Waters MJ 2008 The extracellular domain of the growth hormone receptor interacts with coactivator activator to promote cell proliferation. Molecular Endocrinology 22 2190-2202. (doi:10.1210/me.2008-0128)

Coolican SA, Samuel DS, Ewton DZ, McWade FJ \& Florini JR 1997 The mitogenic and myogenic actions of insulin-like growth factors 
utilize distinct signaling pathways. Journal of Biological Chemistry 272 6653-6662. (doi:10.1074/jbc.272.10.6653)

Fernandes JMO, MacKenzie MG, Wright PA, Steele SL, Suzuki Y, Kinghorn JR \& Johnston IA 2006 Myogenin in model pufferfish species: Comparative genomic analysis and thermal plasticity of expression during early development. Comparative Biochemistry and Physiology. Part D, Genomics \& Proteomics 1 35-45. (doi:10.1016/j.cbd. 2005.09.003)

Figueiredo MA, Mareco EA, Silva MDP \& Marins LF 2012 Muscle-specific growth hormone receptor (GHR) overexpression induces hyperplasia but not hypertrophy in transgenic zebrafish. Transgenic Research $\mathbf{2 1}$ 457-469. (doi:10.1007/s11248-011-9546-2)

Giri DK, Ali-Seyed M, Li LY, Lee DF, Ling P, Bartholomeusz G, Wang SC \& Hung M-C 2005 Endosomal transport of ErbB2: mechanism for nuclear entry of the cell surface receptor. Molecular and Cellular Biology 25 11005-11018. (doi:10.1128/MCB.25.24.11005-11018.2005)

Hawke TJ \& Garry DJ 2001 Myogenic satellite cells: physiology to molecular biology. Journal of Applied Physiology 91 534-551.

Herrington J \& Carter-Su C 2001 Signaling pathways activated by the growth hormone receptor. Trends in Endocrinology and Metabolism 12 252-257. (doi:10.1016/S1043-2760(01)00423-4)

Krolewski JJ 2005 Cytokine and growth factor receptors in the nucleus: whats up with that? Journal of Cellular Biochemistry 95 478-487. (doi:10.1002/jcb.20451)

Liang L, Zhou T, Jiang J, Pierce JH, Gustafson TA \& Frank SJ 1999 Insulin receptor substrate 1 enhances growth hormone-induced proliferation. Endocrinology 140 1972-1983. (doi:10.1210/endo.140.5.6724)

Lichanska AM \& Waters MJ 2008 New insights into growth hormone receptor function and clinical implications. Hormone Research 69 138-145. (doi:10.1159/000112586)

Lo H-W, Ali-Seyed M, Wu Y, Bartholomeusz G, Hsu S-C \& Hung M-C 2006 Nuclear-cytoplasmic transport of EGFR involves receptor endocytosis, importin B1 and CRM1. Journal of Cellular Biochemistry 98 1570-1583. (doi:10.1002/jcb.20876)

Lobie PE, Barnard R \& Waters MJ 1991 The nuclear growth hormone receptor/binding protein. Antigenic and physiochemical characterization. Journal of Biological Chemistry 266 22645-22652.

Lobie PE, Wood TJ, Sliva D, Billestrup N, Waters MJ, Enberg B \& Norstedt G 1994 The cellular mechanism of growth hormone signal transduction. Acta Paediatrica S406 39-46. (doi:10.1111/j.1651-2227.1994. tb13420.x)

Martínez-Moreno CG, Palma L, Carranza M, Harvey S, Arámburo C \& Luna M 2011 Cellular and intracelular distribution of growth hormone in the adult chicken testis. General and Comparative Endocrinology 172 344-357. (doi:10.1016/j.ygcen.2011.03.023)

Mertani HC, Raccurt M, Abbate A, Kindblom J, Törnell J, Billestrup N, Usson Y, Morel G \& Lobie PE 2003 Nuclear translocation and retention of growth hormone. Endocrinology 144 3182-3195. (doi:10.1210/ en.2002-221121)

Moutoussamy S, Kelly PA \& Finidori J 1998 Growth-hormone-receptor and cytokine-receptor-family signaling. European Journal of Biochemistry 255 1-11. (doi:10.1046/j.1432-1327.1998.2550001.x)

Reilly JF \& Maher PA 2001 Importin B-mediated nuclear import of FGF receptor: role in cell proliferation. Journal of Cell Biology 152 1307-1312. (doi:10.1083/jcb.152.6.1307)

Robinson MJ \& Cobb MH 1997 Mitogen-activated protein kinase pathways. Current Opinion in Cell Biology 9 180-186. (doi:10.1016/S0955-0674 (97)80061-0)

Roupas P \& Herington AC 1989 Cellular mechanisms in the processing of growth hormone and its receptor. Molecular and Cellular Endocrinology 61 1-12. (doi:10.1016/0303-7207(89)90184-6)

Sabourin LA \& Rudnicki MA 2000 The molecular regulation of myogenesis. Clinical Genetics 57 16-25. (doi:10.1034/j.1399-0004.2000.570103.x)

Seger R \& Krebs EG 1995 The MAPK signaling cascade. FASEB Journal 9 726-735.

Swanson SM \& Kopchick JJ 2007 Nuclear localization of growth hormone receptor: another age of discovery for cytokine action? Science's Science's STKE 415 pe69. (doi:10.1126/stke.4152007pe69)

Wang S-C \& Hung M-C 2009 Nuclear translocation of the epidermal growth factor receptor family membrane tyrosine kinase receptors. Clinical Cancer Research 15 6484-6489. (doi:10.1158/1078-0432. CCR-08-2813)

Wang Y-N \& Hung M-C 2012 Nuclear functions and subcellular trafficking mechanisms of the epidermal growth factor receptor family. Cell \& Bioscience 2 13. (doi:10.1186/2045-3701-2-13)

Wang Y-N, Yamaguchi H, Hsu J-M \& Hung M-C 2010 Nuclear trafficking of the epidermal growth factor receptor family. Oncogene 29 3997-4006. (doi:10.1038/onc.2010.157)

Waters MJ, Hoang HN, Fairlie DP, Pelekanos RA \& Brown RJ 2006 New insights into growth hormone action. Journal of Molecular Endocrinology 36 1-7. (doi:10.1677/jme.1.01933)

Wu Y-C, Zhu M \& Robertson DM 2012 Novel nuclear localization and potential function of insulin-like growth factor1 receptor/insulin receptor hybrid in corneal epithelial cells. PLoS ONE 7 e42483. (doi:10.1371/journal.pone.0042483)

Zhu T, Ling L \& Lobie PE 2002 Identification of a JAK2-independent pathway regulating growth hormone (GH)-stimulated p44/42 mitogen-activated protein kinase activity. GH activation of Ral and phospholipase Dis Src-dependent. Journal of Biological Chemistry 277 45592-45603. (doi:10.1074/jbc.M201385200)

Zinchuk V, Zinchuk O \& Okada T 2007 Quantitative colocalization analysis of multicolor confocal immunofluorescence microscopy images: pushing pixels to explore biological phenomena. Acta Histochemica et Cytochemica 40 101-111. (doi:10.1267/ahc.07002)

Received in final form 8 October 2015

Accepted 9 November 2015

Accepted Preprint published online 9 November 2015 http://jme.endocrinology-journals.org

DOI: 10.1530/JME-15-0185
(C) 2016 Society for Endocrinology Printed in Great Britain
Published by Bioscientifica Ltd. 